\title{
MESIN PENCACAH SAMPAH ORGANIK SKALA RUMAH TANGGA
}

\author{
I K. G. Wirawan ${ }^{1 *}$, I K. G. Sugita ${ }^{2}$, M. Suarda ${ }^{3}$ dan K. Astawa ${ }^{4}$
}

\begin{abstract}
ABSTRAK
Kecamatan Kuta Utara adalah sebuah kecamatan di Kabupaten Badung, Bali, Indonesia, yang terdiri dari 6 (enam) kelurahan, salah satunya adalah Kerobokan Kaja. Penggunaan pekarangan sebagai lahan untuk tanaman hias di Kerobokan Kaja sangat tinggi hingga mencapai 65\%. Konsekuensi dari banyaknya tanaman hias ini adalah banyaknya sampah dedaunan yang dihasilkan oleh tanaman di masing-masing rumah. Sampah dedaunan ini bisa digunakan sebagai bahan dasar kompos. Dedaunan ini perlu dicacah dengan tujuan untuk memperluas bidang kontaknya, sehingga proses dekomposisi akan semakin cepat terjadi. Oleh karena itu perlu dibuatkan mesin pencacah sampah organik skala rumah tangga. Adapun selain mempercepat proses dekomposisi, mesin pencacah ini juga mereduksi volume sampah organik terutama dedaunan hingga $60 \%$. Dengan adanya alat pencacah sampah organik ini, diharapkan dapat mengurangi volume sampah yang membebani Tempat Pemrosesan Akhir (TPA)
\end{abstract}

Kata kunci : dekomposisi, mesin pencacah, reduksi volume, sampah organik, skala rumah tangga

\begin{abstract}
Kuta Utara is a district in Badung Regency, Bali, Indonesia, which consists of six villages, one of which is Kerobokan Kaja. The use of yards as land for ornamental plants in Kerobokan Kaja is very high, reaching up to $65 \%$. The consequence of this large number of ornamental plants is the amount of leaf waste produced by plants in each house. This leaf litter can be used as a basic material for compost. These leaves need to be chopped in order to expand the contact area so that the decomposition process will be faster. Therefore it is necessary to make a household scale organic waste chopper machine. Aside from speeding up the decomposition process, this chopper machine also reduces the volume of organic waste, especially leaves by up to $60 \%$. With this organic waste chopper, it is expected to reduce the volume of waste that burdens the Final Processing Site.
\end{abstract}

Keywords: decomposition, chopping machines, volume reduction, organic waste, household scale

\footnotetext{
${ }^{1}$ Program Studi Teknik Mesin Fakultas Teknik Universitas Udayana, ikgwirawan@unud.ac.id

2 Program Studi Teknik Mesin Fakultas Teknik Universitas Udayana, tutdegita@unud.ac.id

${ }^{3}$ Program Studi Teknik Mesin Fakultas Teknik Universitas Udayana, made.suarda@unud.ac.id

${ }^{4}$ Program Studi Teknik Mesin Fakultas Teknik Universitas Udayana, awatsa@yahoo.com
} 


\section{PENDAHULUAN}

Kecamatan Kuta Utara adalah sebuah kecamatan di Kabupaten Badung, Bali, Indonesia, dengan wilayah seluas $33.86 \mathrm{~km}^{2}$.(Kecamatan Kuta Utara dalam angka, 2018). Luas wilayah menurut penggunaan ditampilkan pada Tabel 1.1.

Tabel 1.1. Luas wilayah menurut penggunaan di Kecamatan Kuta Utara, 2017

\begin{tabular}{lccccccc}
\hline \multicolumn{1}{c}{$\begin{array}{c}\text { Desa/ } \\
\text { Kelurahan }\end{array}$} & $\begin{array}{c}\text { Luas } \\
(\text { Km2) }\end{array}$ & Sawah & Tegal & Pekarangan & Perkebunan & Kuburan & Lainnya \\
\hline $\begin{array}{l}\text { Kerobokan } \\
\text { Kelod }\end{array}$ & 5.26 & 220 & 38 & 226.14 & - & 0.50 & 41.46 \\
\hline Kerobokan & 5.42 & 79 & 8 & 378.93 & - & 0.34 & 75.33 \\
\hline $\begin{array}{l}\text { Kerobokan } \\
\text { Kaja }\end{array}$ & 5.30 & 107 & 20 & 344.23 & - & 1.50 & 57.27 \\
\hline Tibubeneng & 6.50 & 313 & 9 & 267 & - & 6.00 & 55 \\
\hline Canggu & 5.23 & 244 & 23 & 196 & - & 0.80 & 58 \\
\hline Dalung & 6.15 & 294 & 75 & 222.5 & - & 1.50 & 22 \\
\hline
\end{tabular}

Penggunaan pekarangan sebagai lahan untuk tanaman hias di Kelurahan Kerobokan Kaja sangat tinggi mencapai $65 \%$, di bawah Kelurahan Kerobokan sebesar 70\%. Konskuensi dari banyaknya tanaman hias ini adalah banyaknya sampah dedaunan yang dihasilkan oleh tanaman di masingmasing rumah. Sampah dedaunan ini bisa digunakan sebagai bahan dasar kompos. Dedaunan ini perlu dicacah dengan tujuan untuk memperluas bidang kontaknya. Oleh karena itu perlu dibuatkan mesin pencacah daun skala rumah tangga..

\section{MATERI DAN METODE}

\subsection{Alat dan Bahan}

- Besi siku

- Elektode las

- Belt

- Pulley

- Bearing

- Besi silinder

- Pisau pemotong

- Lempeng besi

\subsection{Metode}

Metode pengerjaan mesin pencacah sampah organik ditunjukan oleh Gambar 2.1. 


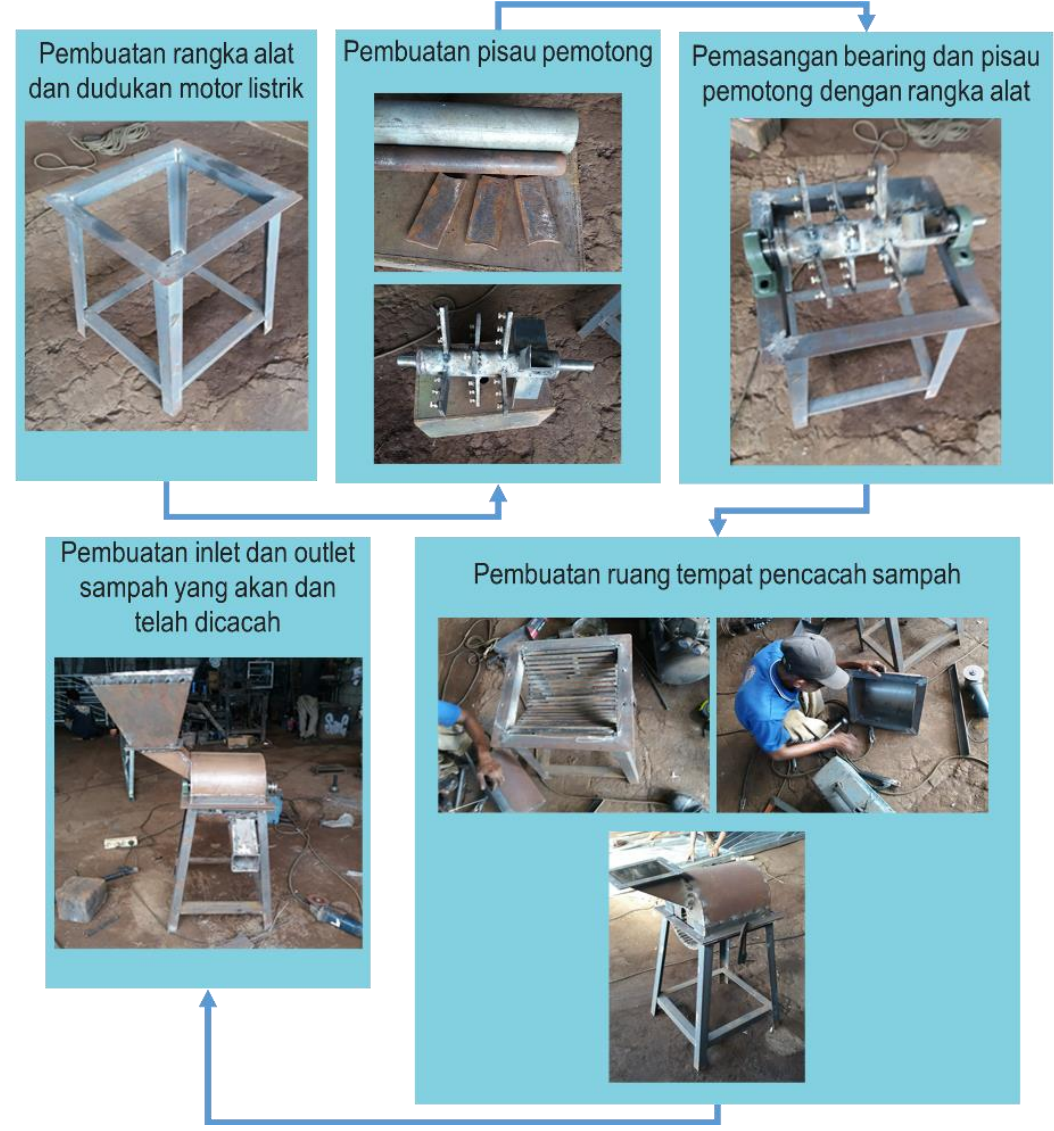

Gambar 2.1. Flowchat Pembuatan Mesin Pencacah Sampah Organik

\section{HASIL DAN PEMBAHASAN}

Hasil yang dicapai pada pengabdian ini berupa produk mesin pencacah sampah organik seperti Gambar 3.1 dan Gambar 3.2. Sampah organik seperti daun dimasukan ke dalam feed. Pisau pemotong diputar oleh motor listrik dan akan memotong sampah.

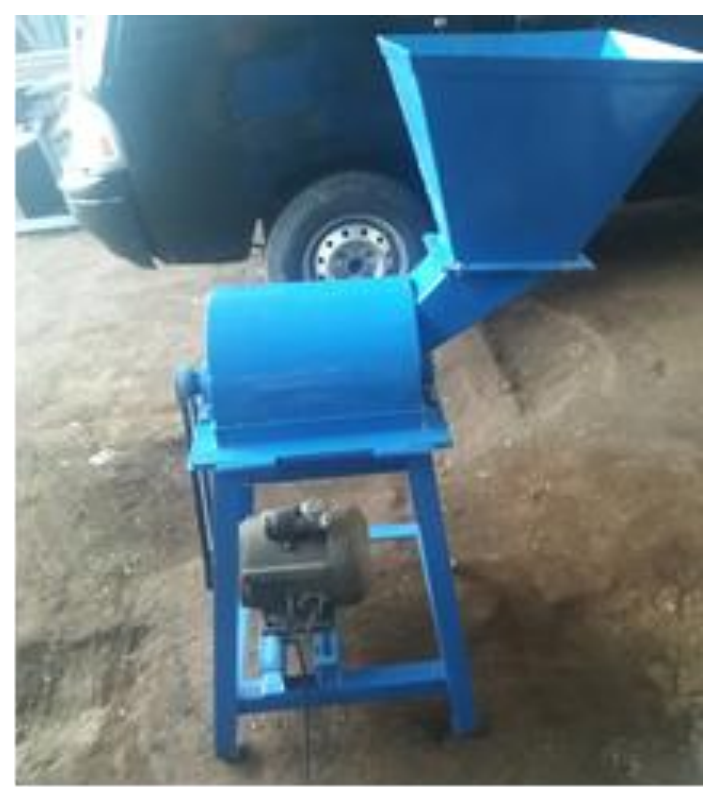


Gambar 3.1. Tampak Depan Alat

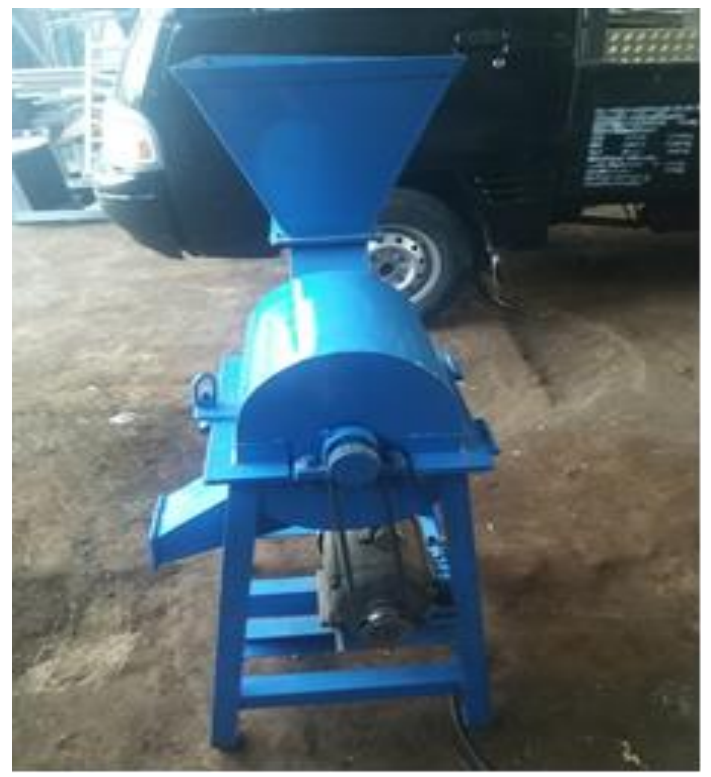

Gambar 3.2. Tampak Samping Alat

Sampah akan tercacah sehingga volume sampah menjadi tereduksi (Gambar 3.3). Sampah organik yang tercacah akan memiliki luas kontak lebih besar sehingga akan lebih mudah terdekomposisi secara alami. Sampah organik yang telah tercacah juga dapat digunakan sebagai bahan dasar untuk pembuatan pupuk kompos. Adapun dalam pengoperasiannya, terdapat permasalahan yang terjadi seperti macetnya alat pencacah akibat adanya cacahan sampah yang tersangkut pada poros putaran pisau. Tersangkutnya cacahan sampah ini disebabkan oleh beberapa hal seperti adanya potongan dari sampah yang memiliki tekstur yang susah terpotong seperti bagian lidi pada busung canang. Selain itu. Sampah organik basah akan menyebabkan hasil cacahan menjadi bertekstur lumpur, yang juga dapat menyebabkan macetnya alat pencacah sampah.

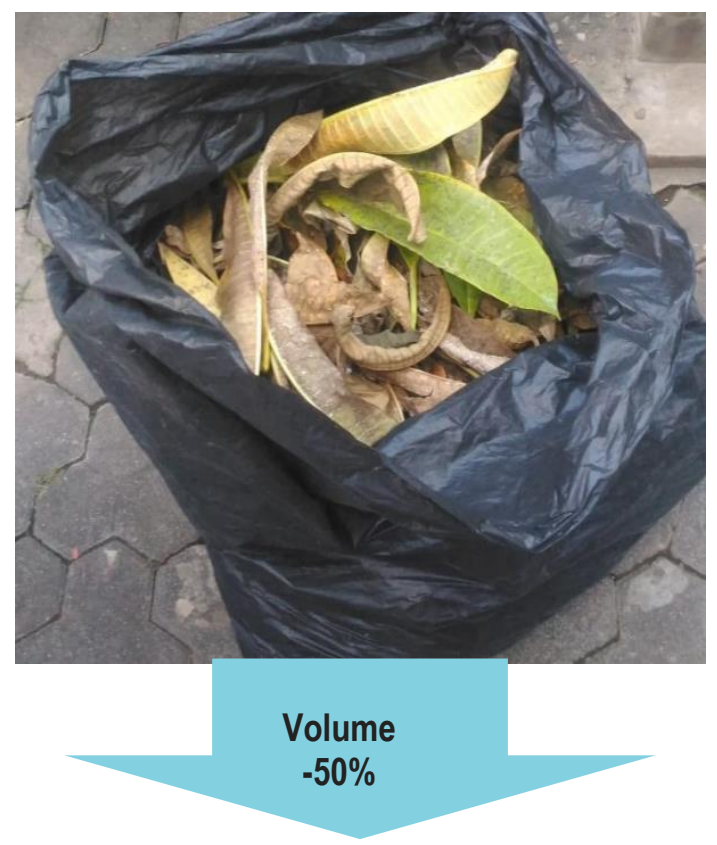




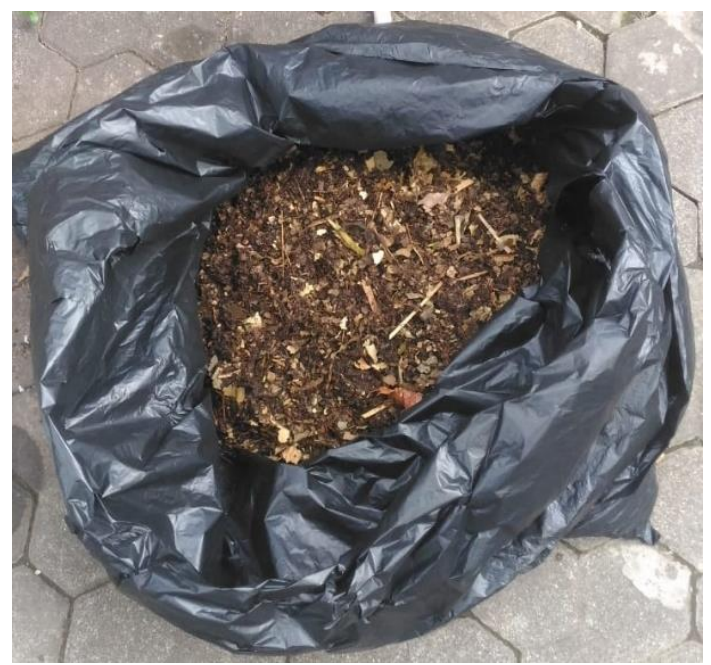

Gambar 3.3. Reduksi Volume Sampah

\section{KESIMPULAN}

Alat pencacah sampah organik skala rumah tangga dibuat dengan menggunakan material besi karena apabila menggunakan material lain seperti kayu, kayu akan mudah rusak akibat adanya bakteri pengurai yang biasanya terdapat pada sampah secara umum. Sampah organik yang telah dicacah akan berkurang volumenya hingga 50\% dan dapat digunakan sebagai bahan dasar untuk pupuk kompos.

Untuk menghindari permasalahan yang terjadi dalam pengoperasian alat seperti macetnya putaran pisau pemotong, pembersihan alat perlu dilakukan setiap selesai penggunaan alat. Selain itu, memasukan sampah organik melalui inlet disarankan secara perlahan untuk memberi waktu pisau pemotong dapat mencacah sampah Sampah organik yang akan dicacah menggunakan alat juga sebaiknya dalam kondisi kering untuk menghindari cacahan sampah bertekstur lumpur.

\section{UCAPAN TERIMA KASIH}

Penulis mengucapkan terimakasih kepada Ketua Lembaga Penelitian dan Pengabdian kepada Masyarakat, Universitas Udayana dengan pendanaan kontrak Nomor: 552 - 22/UN14.4.A/PM/2019.

\section{DAFTAR PUSTAKA}

(2018), Kecamatan Kuta Utara Dalam Angka

, (2018), Statistik Kesejahteraan Rakyat Kabupaten Badung

Aklis, N., \& Masyrukan, M. (2016). Penanganan Sampah Organik dengan Bak Sampah Komposter di Dusun Susukan Kelurahan Susukan Kecamatan Susukan Kabupaten Semarang. Warta LPM, Vol. 19: No.1, pp. 74-82.

Diantoro, P. Y. (2016). Perencanaan Mesin Pencacah Sampah Organik Kapasitas 150-200 Kg/Jam, (Skripsi, Universitas Nusantara PGRI Kediri).

Indriyanti, D. R., Banowati, E., \& Margunani, M. (2015). Pengolahan Limbah Organik Sampah Pasar Menjadi Kompos. Jurnal Abdimas, Vol. 19: No. 1.

Jalaluddin, J., Nasrul, Z. A., \& Syafrina, R. (2017). Pengolahan Sampah Organik Buah-Buahan Menjadi Pupuk dengan Menggunakan Effektive Mikroorganisme. Jurnal Teknologi Kimia Unimal, Vol. 5: No. 1, pp. 17 29 . 
Mardika, A. P. (2015). Perancangan Mesin Pencacah Sampah Organik Skala Rumah Tangga 3 Liter/Proses (Doctoral Dissertation, University Of Muhammadiyah Malang).

Rahayu, D. E., \& Sukmono, Y. (2013). Kajian Potensi Pemanfaatan Sampah Organik Pasar berdasarkan Karakteristiknya (Studi Kasus Pasar Segiri Kota Samarinda). Jurnal Sains dan Teknologi Lingkungan, Vol. 5: No. 2, pp. 77-90.

Sulistyorini, L. (2005). Pengelolaan sampah dengan cara menjadikannya kompos. Jurnal Kesehatan Lingkungan, Vol. 2: No. 1.

Yamin, M., Satyadarma, D., \& Naipospos, P. (2008). Perancangan Mesin Pencacah Sampah Type Crusher. In Proceeding, Seminar Ilmiah Nasional Komputer dan Sistem Intelijen (KOMMIT 2008). Gunadarma University. 